\title{
Avaliação da aprendizagem no contexto do ensino remoto: desafios e possibilidades
}

\author{
The assessment of learning in the context of remote education: challenges and \\ possibilities
}

\section{La evaluación del aprendizaje en el contexto de la enseñanza remota: retos y posibilidades}

\author{
Erica Dantas da Silva ${ }^{1}$ \\ Maria da Conceição Costa ${ }^{2}$ \\ Adriana Moreira de Souza Corrêa ${ }^{3}$
}

\section{Resumo}

Em decorrência da emergência do ensino remoto, uma prática mediada por tecnologias digitais, várias atividades realizadas pelos docentes precisaram ser refletidas, entre elas, a avaliação da aprendizagem. Assim, este estudo busca discutir os limites e as possibilidades da avaliação da aprendizagem no contexto do ensino remoto nos anos iniciais do Ensino Fundamental. A pesquisa caracteriza-se como exploratória, no que se refere aos objetivos; bibliográfica quanto aos procedimentos de coleta de dados e qualitativa no que se refere à abordagem da análise dos dados. Os resultados apontaram que os principais desafios à redefinição do trabalho docente são à concepção da avaliação como o exame, a definição dos critérios de avaliação, bem como a ausência de equipamentos eletrônicos, acesso restrito à internet e conhecimentos para o manuseio dos instrumentos avaliativos no meio digital. Quanto às possibilidades, elencamos a análise das condições de acesso à tecnologia digital pelos estudantes, o entendimento da avaliação como um momento pedagógico que visa redirecionar os percursos da aprendizagem, o uso de instrumentos de avaliação diversificados, o fortalecimento da relação professor-aluno e a prática da autoavaliação.

Palavras-chave: Avaliação; Ensino remoto; Desafios; Possibilidades.

\begin{abstract}
${ }^{1}$ Mestranda em Ensino pela Universidade do Estado do Rio Grande do Norte; Pós-Graduada em Docência do Ensino Superior pela Universidade Federal de Campina Grande; Licenciada em Pedagogia pela Universidade Federal de Campina Grande; Pau dos Ferros, Brasil; E-mail: ericadantasdasilva70@gmail.com; ORCID: https://orcid.org/0000-0001-5886-1151; Lattes: http://lattes.cnpq.br/7256114894339316.

${ }^{2}$ Doutora em Educação pela Universidade de São Paulo; Mestra em Educação pela Universidade Federal do Rio Grande do Norte; Licenciada em Pedagogia pela Universidade do Estado do Rio Grande do Norte; Professora permanente do Mestrado Acadêmico em Ensino do Programa de Pós-graduação em Ensino - PPGE da UERN; Pau dos Ferros, Brasil; E-mail: ceicaomcc@hotmail.com; ORCID: https://orcid.org/0000-0003-0096-4267; Lattes: http://lattes.cnpq.br/4978905417125707.

${ }_{3}^{3}$ Mestra em Ensino pela Universidade do Estado do Rio Grande do Norte; Bacharela em Letras-Libras pela Universidade Federal de Santa Catarina; Licenciada em Pedagogia pela Universidade Federal do Ceará; Professora Assistente da Universidade Federal de Campina Grande; Cajazeiras, Brasil; E-mail: adriana.korrea@gmail.com; $\quad$ ORCID: $\quad$ https://orcid.org/0000-0002-2060-4739; $\quad$ Lattes:
\end{abstract} http://lattes.cnpq.br/7748176565683643.

Revista Devir Educação, Lavras, vol.5, n2., p.267-289 jul./dez., 2021. 
As a result of the emergence of remote teaching, a practice mediated by digital technologies, several activities performed by teachers needed to be reflected upon, among them, the assessment of learning. Thus, this study seeks to discuss the limits and possibilities of learning evaluation in the context of remote teaching in the early years of elementary school. The research is characterized as exploratory as far as the objectives are concerned; bibliographical as far as the data collection procedures are concerned, and qualitative as far as the data analysis approach is concerned. The results pointed out that the main challenges to the redefinition of the teaching work are the conception of evaluation as an exam, the definition of the evaluation criteria, as well as the absence of electronic equipment, restricted internet access and knowledge to handle the evaluation instruments in the digital environment. As for the possibilities, we list the analysis of the conditions of access to digital technology by students, the understanding of assessment as a pedagogical moment that aims to redirect the learning paths, the use of diversified assessment instruments, the strengthening of the teacher-student relationship, and the practice of self-evaluation.

Keywords: Evaluation; Remote learning; Challenges; Possibilities.

\section{Resumen}

En resultado de la aparición de la enseñanza a distancia, una práctica mediada por las tecnologías digitales, es necesario reflejar varias actividades realizadas por los profesores, entre ellas, la evaluación del aprendizaje. Así, este estudio pretende discutir los límites y las posibilidades de la evaluación del aprendizaje en el contexto de la enseñanza a distancia en los primeros años de la educación primaria. La investigación se caracteriza por ser exploratoria en cuanto a los objetivos; bibliográfica en cuanto a los procedimientos de recogida de datos y cualitativa en cuanto al enfoque de análisis de datos. Los resultados señalaron que los principales retos para la redefinición de la labor docente son la concepción de la evaluación como examen, la definición de los criterios de evaluación, así como la ausencia de equipos electrónicos, el acceso restringido a Internet y los conocimientos para manejar los instrumentos de evaluación en el entorno digital. En cuanto a las posibilidades, enumeramos el análisis de las condiciones de acceso a la tecnología digital por parte de los alumnos, la comprensión de la evaluación como un momento pedagógico que pretende reorientar las trayectorias de aprendizaje, el uso de instrumentos de evaluación diversificados, el fortalecimiento de la relación profesor-alumno y la práctica de la autoevaluación.

Palabras clave: Evaluación; Aprendizaje a distancia; Retos; Posibilidades.

\section{Introdução}

Em janeiro de 2020, localizado na cidade de Wuhan, na China, foi identificada uma nova variação viral que ocasiona pneumonia severa. Ela se destacou pela grande transmissividade, rápida evolução nos sintomas, prejuízos causados ao sistema respiratório dos pacientes bem como pelos altos índices de mortalidade (ANTUNES et al., 2020).

Revista Devir Educação, Lavras, vol.5, n2., p.267-289 jul./dez., 2021. 
Conforme elucidam Vianna, Barbosa-Lima e Araújo (2021), somente em 11 de março de 2020, a Organização Mundial de Saúde (OMS) classificou a situação como pandemia e, entre os meses de janeiro e março, o vírus já havia alcançado 118 mil casos (com 4.291 mortos) em 114 países. Nesse sentido, a crise sanitária global, em decorrência desse vírus, rapidamente atingiu todos os setores da sociedade.

No Brasil, o primeiro caso foi confirmado no dia 25 de fevereiro de 2020 (ANTUNES et al., 2020) por isso, foi necessário discutir e constituir alternativas para a contenção do vírus. Essas medidas foram sentidas em diferentes âmbitos sociais entre eles, nas instituições educacionais que, em 17 de março de 2020, foram informadas, pela Portaria do Ministério da Educação (MEC) no 343 (BRASIL, 2020a), da autorização de substituição das aulas que ocorriam de maneira presencial, para acontecer no formato do ensino remoto emergencial. Esse modelo de ensino, que tem o uso da tecnologia digital como principal recurso mediador das interações entre estudantes e docentes, foi reafirmado em documentos oficiais posteriores, a exemplo da Portaria do MEC n 544 (BRASIL, 2020b) publicada em junho do mesmo ano.

Nessa acepção, o ensino remoto ou a aula remota se configura em uma modalidade de aula em que os professores e os estudantes estão distantes geograficamente e, que esse formato de promoção de atividades educacionais foi inserido no Brasil em função da pandemia do novo coronavírus (MOREIRA e SCHLEMMER, 2020)

Ressaltamos que o ensino remoto se trata de uma proposta diferente da Educação à Distância (EaD) prevista na Lei de Diretrizes e Bases da Educação Nacional (LDB) (BRASIL, 1996) tendo em vista que essa última prevê a organização e recursos diferenciados para o planejamento e organização das práticas pedagógicas desde a sua gênese e o ensino remoto é uma prática adotada em função de uma situação emergencial.

Diante disso, os docentes precisaram, em face dessa demanda, criar métodos de trabalho e maneiras de organização dessa modalidade de ensino. Entretanto, além do curto espaço de tempo para a implementação dessa modalidade de ensino sem precedentes ou estudos que direcionassem as práticas pedagógicas, a diversidade de realidades econômicas, sociais e educacionais no Brasil constituiu-se em mais um dos complexos desafios que perpassaram a implementação dessa modalidade de ensino (BARBERIA; CANTARELLI; SCHMALZ, 2021).

Diante deste cenário, a utilização da tecnologia digital no ensino remoto tornou-se importante aliada para a continuidade das atividades educacionais em diferentes níveis e 
etapas de ensino e requereu dos professores a adaptação das formas de trabalhar os conteúdos e desenvolver as habilidades previstas no currículo (GRANDISOLI, JACOBI E MARCHINI, 2020).

Os autores supracitados afirmam que a pandemia, tornou a conjuntura educacional ainda mais desafiadora tendo em vista que evidenciou as disparidades de acesso aos recursos didáticos e tecnológicos que contribuem com a aprendizagem. Em face do exposto, as possibilidades de ensino e, consequentemente, a avaliação da aprendizagem, necessitaram ser compreendidas de forma profunda, para agregar novos conhecimentos e delinear possibilidades que favorecessem o aprendizado do estudante no ensino remoto.

Dentre os aspectos que permeiam a prática docente, o foco deste estudo, é a avaliação da aprendizagem que, para Hoffmann (2005) e Luckesi (2013, 2018) é um momento da prática pedagógica que permite ao docente compreender o processo de ensino e identificar as mudanças necessárias para favorecer o desenvolvimento do estudante. Para tanto, centramos as nossas discussões em aspectos como: o que está sendo avaliado e os processos utilizados na efetivação da avaliação da aprendizagem no período de ensino remoto para os anos iniciais do Ensino Fundamental.

Face ao exposto, o referido estudo, objetiva investigar as percepções presentes na literatura científica sobre a avaliação da aprendizagem nos anos iniciais do Ensino Fundamental no contexto do Ensino Remoto, para identificarmos os desafios e as possibilidades inerentes a esse processo.

Justificamos a efetivação deste estudo pela relevância de entendermos as compreensões e propostas de concretização, presentes na literatura científica, sobre a avaliação da aprendizagem nesse momento atípico do ensino vivenciado no âmbito educacional. Para isso, realizamos uma pesquisa, que segundo Prodanov e Freitas (2013), se caracteriza como exploratória, no que se refere aos objetivos; bibliográfica quanto aos procedimentos de coleta de dados e qualitativa no que se refere à abordagem da análise dos dados.

Esse artigo está organizado em três seções que seguem a introdução e antecedem as considerações finais. Na primeira seção, trazemos reflexões sobre a avaliação pautadas em Hoffmann (2005), Luckesi (2013; 2018) entre outros autores; na segunda abordamos os desafios à implementação da avaliação na perspectiva do ensino remoto; e, na terceira 
elencamos algumas possibilidades para o processo avaliativo que podem favorecer a prática do professor no ensino remoto.

\section{O que é avaliação da aprendizagem?}

A avaliação da aprendizagem é um momento da prática pedagógica voltado para analisar o desenvolvimento do estudante. Conforme apresenta Luckesi (2018), podemos classificá-la com base em cinco elementos: pelo momento da ação; com base na dimensão do tempo utilizado; em função dos seus resultados; considerando a filosofia educacional e sob a análise do sujeito que a realiza.

Segundo o autor supracitado se tomarmos por base o uso dos seus resultados da ação de avaliar, é possível discernir dois papéis da avaliação: o papel diagnóstico ou o papel classificatório. A avaliação com papel classificatório, desconsidera o processo de ensino e a construção da aprendizagem, pois o foco está no uso dos resultados, ao passo que a avaliação diagnóstica compreende a realização de atividades que buscam conhecer a realidade dos estudantes e, a partir disso, é usada para planejar ou reorganizar atividades que visam promover a aprendizagem (LUCKESI, 2018).

Sousa (2009), explica que, antes da Lei de Diretrizes e Bases da Educação Nacional (LDB) de 1961, o objetivo da avaliação era classificatório. Assim, a ação avaliativa era praticada na perspectiva do exame e a análise da compreensão do assunto pelo estudante era realizada através de um instrumento denominado prova. $\mathrm{O}$ tipo mais comum de prova era $\mathrm{o}$ exame escrito, sistematizado no século XVI, cujo objetivo era categorizar os estudantes a partir das notas atribuídas pelo professor. Essas notas, no que lhe concerne, eram os dados utilizados para determinar a aprovação ou a reprovação.

Luckesi (2013) afirma ainda que a compreensão sobre a aprendizagem, na época, se pautava em uma seletividade social, cujos estudantes que possuíam notas e conceitos acima da média, determinada pela escola, eram considerados aqueles que apresentavam aprendizagem satisfatória para aprovação. Já os estudantes que obtinham resultados abaixo desse padrão esperado recebiam menor atenção dos educadores e, consequentemente, tinham as suas dificuldades agravadas em função da ausência de um trabalho específico que os auxiliasse a superar as suas dificuldades.

Revista Devir Educação, Lavras, vol.5, n2., p.267-289 jul./dez., 2021. 


\section{OO DEVIR EDUCAÇÃO}

ISSN: 2526-849X

O autor supracitado explica ainda que o exame funciona como um instrumento de avaliação que, em simultâneo, uniformiza a interpretação das informações e padroniza a aprendizagem e a compreensão do estudante sobre o assunto. Isso ocorre porque apenas parte dos conteúdos são analisados e por esses instrumentos avaliativos admitirem apenas uma resposta correta. Sobre essa prática, o autor explica ainda que a:

[...] carga de ameaça e castigo sobre os educandos, cujo objetivo é pressionálos, para que disciplinadamente estudem, aprendam e assumam condutas, muitas vezes, além de externas a eles mesmos, também aversivas. [...] A permanência desse modo de uso dos exames escolares criou, ao longo dos cinco séculos da modernidade, um padrão de conduta arraigado no modo de conceber e agir dos educandos (LUCKESI, 2013, p. 63).

Diante da afirmação do autor, percebemos que o modelo de avaliação descrito está associado a um perfil de estudante e, nesse caso, a educação visa à formação padronizada e acrítica à medida que busca moldar comportamentos e percepções de mundo sob a ótica da aprovação e reprovação.

Entretanto, mesmo com a modificação do olhar sobre a avaliação reafirmado nas reformulações da LDB, a exemplo da Lei 9.394 (BRASIL, 1996), as práticas de avaliação com papel classificatório ainda podem ser observadas na educação brasileira na atualidade. Desse modo, Luckesi (2013) afirma ser preciso:

[...] assumir a função de subsidiar a construção da aprendizagem bemsucedida. A condição necessária para que isso aconteça é de que a avaliação deixe de ser utilizada como um recurso de autoridade, que decide sobre os destinos do educando, e assume o papel de auxiliar o crescimento (LUCKESI, 2013, p. 177).

Contudo, com as investigações sobre os processos avaliativos e a ampliação das discussões sobre a temática, a avaliação com papel classificatório está, gradualmente, cedendo lugar à compreensão do conceito de avaliação das aprendizagens. Barbosa (2008) assevera que:

A avaliação é uma tarefa didática necessária e permanente do trabalho docente, que deve acompanhar passo a passo o processo de ensino e aprendizagem. Por meio dela, os resultados que vão sendo obtidos no 
decorrer do trabalho conjunto do professor e dos alunos são comparados com os objetivos propostos, a fim de constatar progressos, dificuldades e, também, reorientar o trabalho docente. Assim, a avaliação é uma tarefa complexa que não se resume a realização de provas e atribuições de notas (BARBOSA, 2008, p. 1)

Essa percepção de avaliação é compartilhada por Hoffmann (2005), ao apresentar os fundamentos da avaliação mediadora. A autora afirma que "Avaliar é interpretar um percurso de vida do aluno durante o qual ocorrem mudanças em múltiplas dimensões. Avaliar é acompanhar para promover o processo de construção do conhecimento do educando" (HOFFMANN, 2005, p. 4). Logo, a percepção sobre a avaliação apresentada pela autora tem um papel diagnóstico e busca mediar o entendimento sobre as ações do professor e os seus reflexos no processo de aprendizagem do estudante.

No mesmo sentido, Luckesi (2013) explica que "[...] o ato de avaliar tem como função investigar a qualidade do desempenho dos estudantes, tendo em vista proceder a uma intervenção para a melhoria dos resultados [...]" (LUCKESI, 2013, p. 57). Conforme o autor, a Avaliação Diagnóstica defendida por ele, deve ser compreendida como um dos instrumentos pedagógicos que o docente dispõe para nortear o seu trabalho.

Em complementaridade, Weisz e Sanches (2006) dizem que "avaliar a aprendizagem do aluno é também avaliar a intervenção do professor, já que o ensino deve ser planejado e replanejado em função das aprendizagens conquistadas ou não" (WEISZ e SANCHES, 2006, p. 95). Notamos, nessas afirmações de Hoffmann (2005), Luckesi (2013) e Weisz e Sanches (2006) que a avaliação deve ser entendida como um instrumento que permite analisar a construção do conhecimento pelos estudantes e que, diante disso, requer uma ação ativa do professor no sentido de analisar o percurso educativo trilhado e reorganizar os caminhos para chegar ao objetivo que é a aprendizagem.

Todavia, para isso acontecer, antes de repensarmos os instrumentos avaliativos, é relevante que a concepção de educação seja modificada e a avaliação da aprendizagem, seja entendida como uma ferramenta pedagógica para conhecermos a condição de aprendizagem de cada discente, no que concerne aos conteúdos trabalhados como também às habilidades e competências que precisam ser desenvolvidas pelo estudante.

Trata-se, portanto, de um processo contínuo por isso, o educando deve ser avaliado no transcorrer do ano letivo, em diferentes momentos da rotina escolar e com instrumentos 
diversificados que requeiram linguagens diferentes para a expressão do conhecimento (SANTOS, 2010).

Em síntese, podemos afirmar que o ato de avaliar é complexo e que, mesmo antes da pandemia da COVID-19, esse momento didático trazia inquietações para os docentes e os estudantes. Assim, a modificação dos espaços e das práticas pedagógicas, decorrentes de acentuadas transformações nas rotinas pedagógicas que passaram a ocorrer mediadas pela tecnologia, acompanharam a necessidade de mudanças na concepção e prática de avaliação.

Nesse sentido, o acesso à tecnologia digital necessária para participar das atividades, as destrezas necessárias para a utilização desses recursos digitais, a falta de compartilhamento do ambiente escolar bem como dos relacionamentos síncronos e presenciais vivenciados com os educadores e com outros estudantes na escola constituem-se em fatores econômicos e emocionais que podem interferir no aprendizado dos estudantes.

Barberia, Cantarelli e Schmalz (2021), pesquisadores do Departamento de Ciência Política da Universidade de São Paulo (USP), ao analisarem os programas de educação pública dos estados e capitais brasileiras no período remoto, entre março e outubro de 2020, relataram que nesse período, menos de $15 \%$ distribuíram dispositivos digitais aos estudantes e menos de $10 \%$ proveram o acesso à internet à população em vulnerabilidade econômica matriculada na escola.

Nessa pesquisa, os autores analisaram os meios e canais para a transmissão das aulas, as formas de acesso do estudante (materiais, dispositivos e tecnologia), a supervisão dos alunos (participação nas atividades) e os níveis de educação atendidos. Diante desses dados concluíram que os planos e a sua execução contribuíram para evidenciar as desigualdades sociais que já existiam antes da pandemia.

Notamos, desse modo, que a pandemia destacou, de forma evidente, as desigualdades sociais e econômicas que impactam diretamente no acesso e direito à educação de muitos estudantes. Evidentemente, esta conjuntura deve ser considerada no momento de avaliá-los, haja vista que as condições para a promoção da aprendizagem são diversas. Em face disso, o docente necessita entender o contexto social dos discentes com os quais trabalha e se posicionar de maneira solidária, empática e, porque esse é um dos princípios da avaliação da aprendizagem. Nesse sentido, Cavalcanti Neto e Aquino (2009) dizem que:

Revista Devir Educação, Lavras, vol.5, n2., p.267-289 jul./dez., 2021. 
Além de diagnosticar, a avaliação tem a função de propiciar a auto compreensão do nível e das condições em que se encontram tanto o educando quanto o educador. Esse reconhecimento do limite e da amplitude de onde se está possibilita uma motivação e a consequente contribuição tanto para auxílio quanto para o aprofundamento da aprendizagem (CAVALCANTI NETO e AQUINO, 2009, p. 228).

Desse modo, as autoras reafirmam que o principal objetivo da avaliação da aprendizagem é identificar o nível de aprendizagem dos discentes, aprimorar e adaptar as estratégias adotadas, refazer ou readaptar o planejamento para que as dificuldades dos educandos sejam mitigadas.

Partindo do princípio de superação da ideia da educação como reprodutora de comportamentos, como afirmou Sousa (2009), consideramos que os estudantes devem ser autônomos, protagonistas, criativos e críticos na construção do conhecimento, de modo a identificar as situações nas quais o saber construído pode ser utilizado em seu cotidiano.

Enfatizamos, assim, que no ensino remoto emergencial, diante das adversidades e limitações anteriormente elencadas, torna-se urgente pensarmos em uma avaliação que estimule a imaginação, a criatividade, o pensamento crítico, a reflexividade e as demais habilidades que o educando possa desenvolver. Essas habilidades e conhecimentos podem ser estimulados com a inserção de recursos do campo tecnológico, como a incorporação de plataformas virtuais e das mídias digitais que permitem a integração de diferentes linguagens e formatos de divulgação dos saberes construídos.

Nesse sentido, entendemos que as modificações nas formas de ensinar e aprender podem fomentar a reflexão do trabalho docente no sentido de utilizar esses recursos de maneira ética e afetiva para a utilização de vários modos de avaliar as aprendizagens dos educandos.

\section{Do ensino presencial à adaptação ao ensino remoto: desafios apontados}

O período remoto emergencial ampliou as inquietações dos docentes sobre o ensino e, consequentemente, sobre o processo de avaliação dos estudantes em função de vários fatores, entre eles, o próprio acesso dos estudantes aos instrumentos utilizados na avaliação. Em contrapartida, em função das modificações da prática avaliativa, esse momento do ensino é fundamental para a aprendizagem, haja vista que através da avaliação, o docente pode 
acompanhar o desenvolvimento do discente no que concerne aos seus avanços ou dificuldades e, a partir daí, ponderar as possíveis intervenções a serem realizadas para favorecer a construção do conhecimento.

Conforme Palú, Schütz e Mayer (2020), ao atravessarmos períodos como o que vivemos atualmente as reflexões sobre o ensino e suas respectivas mudanças se fazem necessárias para a continuidade do trabalho da escola. A esse respeito, Schlemmer, Felice e Serra (2020) destacam que:

Estamos vivendo uma mudança na ecologia da aprendizagem, um movimento propício para a passagem de uma escola feita de salas de aulas e aulas, para uma ecologia de plataformas de dados, de acesso, de co-produção e compartilhamento de conteúdo de forma interativa (SCHLEMMER, FELICE e SERRA, 2020, p. 18).

Diante disso, devemos nos apropriar do uso da tecnologia digital para mitigar as barreiras presentes no contexto atual sem esquecer de nos debruçarmos sobre o elemento humano envolvido nessas relações, ou seja, sobre os impactos e as limitações encontradas pelo professor e pelo estudante para participar do processo educativo. Entre essas limitações citamos os efeitos do distanciamento social que dificulta ao docente realizar um acompanhamento customizado, com intervenções síncronas diante da análise das dificuldades apresentadas no desenvolvimento do estudante nas atividades realizadas.

Assim, a relação professor-aluno que é substancial ao processo de ensino e aprendizagem será, por hora, esmaecida no fluxo educacional. Sobre essa relação, Oliveira et al. (2013) destaca que as demonstrações de afeto que existem na relação professor-aluno podem trazer contributos tanto para o aprendizado do educando quanto para o crescimento do professor. No mesmo sentido, António Nóvoa (2020) enfatiza não haver um processo educativo desprovido da dimensão humana e essa relação se fortaleza no contato físico entre os indivíduos que fazem parte deste processo.

Oliveira et al. (2013) salienta ainda que essa interação é primordial, inclusive, para sanar muitas das dificuldades de aprendizagem dos educandos que podem, em alguns casos, estar associadas à metodologia utilizada pelo professor. Contudo, com a interação mediada pela tecnologia digital, novas formas de demonstrar e receber afeto e realizar um atendimento específico às necessidades apresentadas pelos discentes precisam ser construídas. Nesse 
sentido, os docentes deverão estar cientes e empenhados em compreender a atual conjuntura e buscar alternativas para mitigar os efeitos dessa crise.

Ao analisar as práticas pedagógicas desenvolvidas no ensino presencial, Schön (1997) explicou que "existem situações conflitantes, desafiantes, que a aplicação de técnicas convencionais, simplesmente não resolve problemas" (SCHÖN, 1997, p. 21), e ao analisarmos a conjuntura atual, notamos que essa afirmação continua a ser válida na situação do ensino remoto emergencial.

Corroborando com este entendimento, Belotti e Faria (2010) ressaltam a necessidade de o docente desenvolver uma reflexão contínua sobre a sua prática e conduzi-la em consonância a realidade em que trabalha. Diante disso, a prática pedagógica precisa estar direcionada às necessidades dos seus estudantes. Para isso, o docente precisa buscar novas direções, sempre que necessário, para tornar o aprendizado um processo estimulante e desafiador para cada educando.

Hodges et al. (2020) explicita que o ensino remoto emergencial requereu uma adaptação curricular temporária como alternativa para acontecerem as atividades escolares relacionadas às diversas disciplinas. Isso decorre das circunstâncias de crise sanitária e das suas implicações no bem-estar físico e mental dos educadores e dos estudantes.

Em face dessa conjuntura, os autores elencam algumas possibilidades que se delinearam em função das características identificadas pelos sistemas educacionais: o uso de soluções de ensino totalmente remotas pautadas na adaptação das estratégias utilizadas no formato presencial, ou o ensino de forma híbrida, que requer o uso de metodologias que podem diferir daquelas utilizadas nas práticas presenciais. Independente da forma escolhida para propor atividades no ensino remoto, um dos desafios que se faz presente é estimular o engajamento dos estudantes de forma que eles participem, de modo ativo, do processo de aprendizagem.

Acreditamos que, independentemente da proposta adotada, o professor necessita desenvolver atividades que desafiem os estudantes, de modo que eles possam interagir, participar, criar, produzir, discutir e refletir com seus professores e colegas, para debater sobre o contexto vivenciado na pandemia e utilizar esses momentos para promoção de outras aprendizagens. A participação nessas atividades, no que lhe concerne, traz indícios sobre o processo de desenvolvimento dos estudantes que podem ser utilizados pelos docentes como elementos para a avaliação da aprendizagem.

Revista Devir Educação, Lavras, vol.5, n2., p.267-289 jul./dez., 2021. 
Na acepção de Silva (2006), a avaliação desempenha papel relevante enquanto instrumento sistemático de acompanhamento da aprendizagem. De acordo com Luckesi (2013), o que é essencial, precisa ser investigado e como investigação do estado de aprendizagem dos discentes, a avaliação produz conhecimento acerca dos processos singulares de cada aluno.

Em complementaridade Hoffmann (2011) explica que a avaliação deve estar pautada em instrumentos diversificados, flexíveis e que atendam às características e as necessidades dos estudantes, bem como considerar o ambiente em que o processo de ensino-aprendizagem acontece. Dessa maneira, o ato de avaliar poderá contribuir para remodelar o processo de ensino para favorecer o alcance dos objetivos previamente estabelecidos.

Face ao exposto, no ensino remoto emergencial, o docente tem o desafio de aprender a utilizar, com competência, as Tecnologias Digitais de Informação e Comunicação (TDIC's) para diversificar, à medida do possível, as práticas educativas e os instrumentos avaliativos, de forma que a avaliação do estudante ocorra de maneira inclusiva, igualitária e equânime. Desse modo, o professor pode assegurar ao estudante o direito democrático de acesso ao ensino, com atividades e propostas que viabilizem a sua aprendizagem.

Essa necessidade de inserção da tecnologia na prática educativa é um assunto debatido antes da pandemia da COVID-19. Em 2011, Bittencourt afirmou que:

As transformações tecnológicas têm afetado todas as formas de comunicação e introduzido novos referenciais para a produção de conhecimento, e tal constatação interfere em qualquer proposta de mudança dos métodos de ensino. [...] as atuais gerações convivem com informações obtidas por imagens e sons, e essa situação tem provocado mudanças substantivas na escolarização. Crianças e jovens assistem noticiários, filmes, novelas, desenhos animados, programas de entrevista, futebol e estão assim imersos em um 'oceano de imagem' (BITTENCOURT, 2011, p. 106-107 grifos do autor).

No ensino remoto, essa afirmação torna-se ainda mais evidente e a inserção dessas práticas traz desafios aos docentes. Esses desafios são referentes à construção de um novo perfil profissional adequado às novas demandas que implicam o planejamento, o trabalho e a avaliação da aprendizagem do estudante. Nesse sentido, Moreira, Henriques e Barros (2020) explicam que, nesse formato de ensino, ao "[...] professor recaem, pois, as funções de 


\section{OO DEVIR EDUCAÇÃO}

ISSN: 2526-849X

motivador, de criador de recursos digitais, de avaliador de aprendizagens e de dinamizador de grupos e interações online” (MOREIRA, HENRIQUES e BARROS, 2020, p. 354).

Tais mudanças requerem um corpo docente articulado, que dialoga e aprende sobre comunicação, sobre a tecnologia digital e acerca da educação na perspectiva do ensino remoto. Desse modo, enquanto vivenciarmos práticas pedagógicas nessa modalidade de ensino, o professor precisa aprender, constantemente, de modo a desenvolver práticas inovadoras, em favor do desenvolvimento da autonomia do discente. Nessa perspectiva, além de refletir e implementar atividades a favor da aprendizagem, é necessário de refletir sobre práticas avaliativas que permitam identificar as competências e habilidades construídas pelo discente.

No ensino remoto, além das atividades impostas aos professores, os discentes também se deparam com uma realidade diferente daquela, em que estavam habituados. Desse modo, os estudantes podem apresentar dificuldades na organização do tempo, lugares e formas de estudo, desenvolvimento da autonomia; deparar-se com a ausência de equipamentos eletrônicos, a instabilidade ou a ausência de internet; a inexistência de um espaço apropriado para desenvolver as atividades educativas, dentre tantos outros desafios que se apresentam ao estudante nesse momento.

À vista disso, uma avaliação pontual, cujo enfoque esteja nos resultados e ignore os vários fatores imbricados no processo de aprendizagem é inadequada, pois pode desfavorecer os estudantes privados dos recursos necessários ao acesso às atividades bem como aos recursos que medeiam a produção do conhecimento.

Face ao exposto, práticas pensadas para o ensino presencial podem ser reorganizadas para ocorrer no ensino remoto. Dessa forma, as aulas e as atividades realizadas no ambiente da sala de aula virtual precisam transcorrer de forma interativa de modo que os educandos se sintam parte do processo de aprendizagem. Assim, isso também deve ser considerado na seleção e na aplicação dos instrumentos avaliativos, pois eles também devem ser conduzidos a partir de um olhar participativo, flexível e dinâmico, conforme discutiremos a seguir.

\section{Estratégias pedagógicas como possibilidades avaliativas no ensino remoto}

No ensino presencial ou no ensino remoto emergencial, a avaliação constitui-se uma ferramenta que busca investigar a qualidade do desempenho dos estudantes em relação aos 
conteúdos e habilidades trabalhados pelo educador. Com base nesses resultados, o docente pode analisar a sua prática e planejar outras atividades que proporcionem oportunidades de aprendizado ao estudante. Nesse sentido, Hoffmann (2010) explica que:

A finalidade da avaliação não é descrever, justificar, explicar o que o aluno 'alcançou' em termos de aprendizagem, mas a de desafiá-los todo tempo a ir adiante, a avançar, confiando em suas possibilidades e oferecendo-lhes, sobretudo, o apoio pedagógico adequado a cada um (HOFFMANN, 2010, p. 103 , grifos da autora).

Respaldadas na afirmação da autora, essa concepção de avaliar deve nortear o planejamento de intervenções assertivas para a superação das possíveis lacunas de aprendizagem diagnosticadas com os instrumentos utilizados pelo docente para a avaliação. Por essa razão, o educador necessita dispor de estratégias avaliativas, cujos resultados o permita identificar as defasagens de aprendizagem e, a partir disso, possa criar estratégias de ensino respaldadas no desenvolvimento afetivo, físico, artístico, social e intelectual dos alunos.

À vista disso, abordaremos aqui algumas sugestões dispostas na literatura científica que podem ser desenvolvidas no ambiente da sala de aula virtual como instrumentos de avaliação. Conforme destacamos na seção anterior, faz-se necessário que o docente identifique as novas demandas requeridas ao perfil do educador que atua no ensino remoto, tais como: identificar o acesso dos estudantes à plataforma digital (tanto aos dispositivos quanto a internet) para planejar atividades mais adequadas à realidade; estimular os estudantes na construção de instrumentos que os permitam organizarem o tempo, espaço e estratégia de estudo (resumo, fichamento, respostas à questionários); busque estratégias de aproximação da relação entre professor-aluno para motivá-lo a participar das atividades; utilize instrumentos variados para avaliar e utilize os resultados da avaliação da aprendizagem como subsídios para elaborar os planejamentos de atividades seguintes.

Hoffmann (2012) apresenta algumas orientações sobre o processo avaliativo para o ensino presencial que podem ser utilizadas pelo educador para nortear as suas práticas no ensino remoto, dentre as quais destacamos duas: 1) a necessidade de o docente priorizar propostas educativas que despertem demonstrações de iniciativa, criatividade, compromisso, responsabilidade social, no lugar de valorizar a aprendizagem de conteúdos; 2) propor tempos 
flexíveis de realização de tarefas pelos estudantes, assegurando-lhes acesso virtual aos gestores e professores.

A autora supracitada, discute ainda a necessidade de que as atividades pedagógicas sejam elaboradas no sentido de instigar cada aluno a ser protagonista de sua aprendizagem, levando-o a delinear seu próprio projeto de estudo, organizar maneiras de registrar, anotar, comentar o que está acontecendo entre professores, educandos e familiares. Ao adotar a prática apresentada pela autora, esses registros podem ser utilizados pelo docente como instrumentos de avaliação, pois, neles há informações relevantes sobre o processo e o produto construído pelo estudante. Nesse mesmo sentido, Mercado (2008) salienta que existem "recursos avaliativos que envolvem registros disponíveis na Internet e propiciam uma avaliação contínua no atendimento das comunidades de aprendizagem” (MERCADO, 2008, p. 3).

Sobre esses recursos, o autor elenca: os Mapas cognitivos, que favorecem a pesquisa e a sistematização do conhecimento; o Memorial, que possibilita fazer o registro da própria ação, bem como a análise de suas ações e reações diante deles, como explicações, interpretações, impressões, sentimentos, etc.; construção de blogs com a estrutura de diários de campo ou diários reflexivos, que viabilizam fazer o registro das situações e das observações pessoais para incitar o raciocínio que permeou a delineação do texto, as estratégias e procedimentos desenvolvidos, a contribuição nas atividades entre outros aspectos; participação em fóruns de discussão, que oportuniza a reflexão acerca do assunto bem como a comunicação entre o grupo; Webfólio, constitui-se em um portfólio virtual composto por um conjunto de registros dos processos e produtos das aprendizagens incluindo os sentimentos, as opiniões e as impressões.

Elucidamos, ainda, que os mapas cognitivos, memoriais, blogs, fóruns de discussão e Webfólio também foram indicados por Fachineto et al. (2020) ao apresentam procedimentos que podem ser usados para avaliação de aprendizagem no ensino remoto. Além desses instrumentos, os autores sugerem os trabalhos de grupo, os quizzes e o acompanhamento da participação do educando.

Sobre este aspecto da participação, Laguardia, Portela e Vasconcellos (2007) em um estudo que analisou um período anterior à pandemia, identificaram que entre os instrumentos, frequentemente, usados para a avaliação no ambiente online, estão a avaliação da participação que consiste em avaliar o contributo do educando para a produção do conhecimento do grupo.

Revista Devir Educação, Lavras, vol.5, n2., p.267-289 jul./dez., 2021. 
Em outras palavras, analisa a relevância das colocações, a socialização do conhecimento, das inquietações e das pesquisas realizadas pelo estudante com os demais colegas. Quando delineada a partir de critérios claros, a avaliação da participação do discente pode exprimir a sua própria aprendizagem, como também ampliar a atuação do educando no que concerne à sua própria produção do conhecimento.

Ademais, torna-se substancial diversificarmos as experiências de aprendizagem dos alunos com a utilização de jogos virtuais, textos interativos, podcast, vídeos, projetos coletivos, etc., que estão disponíveis no meio digital. Isso porque, o uso desses recursos oportuniza a aprendizagem dos diferentes componentes curriculares e potencializam o desenvolvimento de uma aprendizagem significativa, mesmo mediante de um cenário permeado por contínuas mudanças e desafios.

Martins (2020) diz que os formulários virtuais podem ser usados como instrumentos de avaliação no ensino remoto. $\mathrm{O}$ autor menciona que, por meio dessa ferramenta, o professor pode produzir questionários específicos para cada componente curricular, sendo eles elaborados com questões de múltipla escolha (com resposta única ou várias respostas corretas); questões com respostas dissertativas; perguntas elaboradas a partir de texto, com suporte de imagem ou de recursos audiovisuais. Os docentes ainda podem inserir recursos como pontuação do participante (no caso de autocorreção), datas e horários de realização da resposta, opções de descrições, inclusão de títulos, dentre outras funcionalidades.

Destacamos ser relevante promover a autoavaliação do estudante, tendo em vista que esta permite ao discente avaliar, de forma crítica, a sua participação e desempenho nas aulas, o tempo que oferece para o estudo, a disposição para realização de tarefas e atividades, bem como o seu desenvolvimento científico, intelectual e cultural. O uso dessa prática de avaliação pode ser profícuo à medida que estimula a promoção da autonomia e do protagonismo do aluno na construção do conhecimento, haja vista que, segundo Hoffmann (2005) " [...] Autoavaliar-se significa o educando promover e acompanhar seu próprio processo de construção de conhecimento [...]” (HOFFMANN, 2005, p. 4).

A autora afirma ainda que a autoavaliação pode promover "[...] espaços de confiança, de diálogo e de oportunidade ao jovem de se comprometer com seus próprios rumos, de definir projetos de estudo, etapas de trabalho, individuais e em grupo" (HOFFMANN, 2005, p. 5). Hoffmann (2012) explica que a autoavaliação pode ocorrer através de atividades como 
diários de bordo, produção de vídeos, organização de portfólios, realização de exercícios com autocorreção e leituras ou materiais complementares pela internet.

No ensino remoto, acreditamos que essa autoavaliação poderá ser feita oralmente, através de chamadas de vídeo ou utilizando a modalidade escrita da língua, por meio do compartilhamento de textos. Ressaltamos, contudo, que independente do instrumento e estratégia utilizados, o professor precisa zelar, o máximo possível, pelo respeito aos alunos e pela ética da responsabilidade no exercício da sua profissão.

Para isso, é preciso, como afirma Franco (2016), buscar o diálogo, o estabelecimento de acordos com sua turma, bem como deixar claro os objetivos e a sua metodologia de trabalho de forma que a sua prática possa trazer contributos para o processo de aprendizagem dos discentes. Desse modo, o momento avaliativo deve estar claro para o professor e para os estudantes, ao invés de ser realizado de maneira automatizada ou para, apenas, atribuir uma nota. Isso porque, uma avaliação delineada de maneira clara, objetiva, com instrumentos variados e cuidadosamente elaborados pode contribuir para a identificação das dificuldades e dos progressos na aprendizagem do discente.

Ressaltamos que no ensino remoto emergencial em função da pandemia da COVID19, a preocupação, desconsolo, aflição, tristeza, medo, ansiedade, dentre tantos outros sentimentos podem trazer prejuízos para a internalização dos saberes escolares. Diante disso, todas as competências, habilidades e conhecimentos demonstrados pelo educando precisam ser considerados no momento da avaliação. Nesse sentido, considerar que o aluno sozinho consegue localizar, ler e produzir textos, realizar as atividades e enviá-las através de plataformas digitais, de forma autônoma, constitui-se como uma razão para avaliar positivamente este discente, pois denota que o estudante se apropriou de práticas de uso da leitura e da escrita no ambiente digital. Portanto, a interação e o convívio, no meio digital, devem ser avaliados pelo docente, pois esses saberes demonstram a resiliência do discente neste período permeado por tantas adversidades.

\section{Considerações Finais}

A pandemia da COVID-19 trouxe vários desafios à educação, entre eles, a avaliação na perspectiva do ensino remoto. Nesse sentido, cabe ao educador e ao sistema educacional a 
identificação de práticas avaliativas, comprometidas, amorosas e éticas que ocorram mediadas pela tecnologia digital.

Assim, no que concerne ao objetivo traçado para este estudo que foi investigar os desafios e as possibilidades para a avaliação da aprendizagem discente nos anos iniciais do Ensino Fundamental no contexto do ensino remoto, notamos serem inúmeros os desafios e que esses remontam à problemas evidenciados pela educação, pelos professores e pelos estudantes há várias décadas.

A própria concepção de avaliação da aprendizagem que busca a atribuição de nota em detrimento de reorganizar as possibilidades de ensino pode se torna um empecilho para o planejamento e realização dessa atividade pedagógica. Em função disso, é necessário analisar a concepção que fundamenta a prática de avaliação que, conforme a LDB vigente é de acompanhar o desenvolvimento dos estudantes para orientar as ações educativas posteriores.

Além dessas barreiras citamos o acesso à tecnologia digital (equipamentos digitais e internet), a formação docente para o uso da tecnologia e inserção da mesma como recurso de aprendizagem, conforme explicitam Laguardia, Portela e Vasconcellos (2007), Bittencourt (2011) entre outros. Associados a isso, surgem as dificuldades dos educandos em se organizarem de forma autônoma, a falta de um espaço adequado para o estudo, o isolamento social, as condições afetivas dentre tantos outros obstáculos que se apresentam ao estudante nesse momento.

Nesse sentido, a pandemia demonstra que a educação necessita de aumento de investimentos em equipamentos, formações e outros recursos que possam melhorar as qualidades de ensino e de aprendizagem. Diante disso, docentes precisam buscar melhorias na educação para todos, entre elas, variar as estratégias de ensino e de avaliação da aprendizagem para entender o processo de desenvolvimento de cada estudante. Um olhar atento precisa ser dedicado àqueles que estão impossibilitados de acessar as plataformas virtuais e ao material didático, em que são privados de realizar as atividades propostas pelos docentes.

No que concerne as possibilidades, identificamos ser necessário entender as possibilidades de acesso ao conhecimento pelos alunos, desenvolver relações amorosas e éticas e promover atividades diversificadas que podem ser realizados remotamente, como: questões dissertativas, pesquisas, construção de Webfólio, mapas cognitivos, produção de vídeos, construções de blogs, podcasts, memoriais, jogos virtuais, textos interativos, projetos

Revista Devir Educação, Lavras, vol.5, n2., p.267-289 jul./dez., 2021. 
coletivos, etc. Esses são alguns recursos de ensino que podem funcionar também como instrumentos de avaliação da aprendizagem.

Em face das discussões tecidas, afirmamos que os instrumentos elencados para serem utilizados no ensino remoto podem ter continuidade na volta às aulas presenciais, dado que se faz necessário considerar os desafios educacionais, sanitários e logísticos do retorno gradual. Dessa forma, o uso de múltiplos instrumentos que permitam a análise dos resultados em uma perspectiva diagnóstica auxiliará neste processo de acompanhamento dos níveis de aprendizagens dos discentes.

Traçar estas discussões foi um tanto complexo, pois os textos pesquisados para compor a base da fundamentação teórica, o estado da arte ou do conhecimento ainda está em construção e se amplia à medida que os docentes e pesquisadores refletem e socializam outros saberes sobre a temática na literatura científica. Isso revela que os professores estão em busca da construção da sua identidade profissional enquanto educadores no ensino remoto em função das descobertas oriundas do exercício da profissão e do seu papel incumbido socialmente em tempos de pandemia, e buscam refletir teoricamente sobre os processos vivenciados na prática, contudo, precisam ser estimulados a ampliar a divulgação dessas práticas para favorecer o desenvolvimento de atividades por outros educadores.

Logo, essa situação, que pode ser entendida como uma adversidade, trouxe contribuições no sentido de fomentar ao docente a reflexão sobre a avaliação e o uso da tecnologia digital no processo educativo, o que acreditamos que sejam reflexões que perpassarão as práticas do ensino presencial por ocasião do retorno às aulas.

\section{Referências}

ANTUNES, Bianca Brandão de Paula et al. Progressão dos casos confirmados de COVID-19 após implantação de medidas de controle. Rev. Bras. Ter. Intensiva, v. 32, n. 2, p. 213 223, 2020. Disponível em:

https://www.scielo.br/j/rbti/a/w5ncnKcbTKRR9LDYVYsj6mg/?lang=pt\&format=pdf. Acesso em: 11 set. 2021.

BARBERIA, Lorena Guadalupe.; CANTARELLI, Luiz Guilherme Roth.; SCHMALZ, Pedro Henrique de Santana. Uma avaliação dos programas de educação pública remota dos estados e capitais brasileiros durante a pandemia do COVID-19. 2021. Disponível em: http://fgvclear.org/site/wp-content/uploads/remote-learning-in-the-covid-19-pandemic-v-1-0portuguese-diagramado-1.pdf. Acesso em: 17 jun. 2021. 
BARBOSA, Jane Rangel Alves. A avaliação da aprendizagem como processo interativo: um desafio para o educador. Democratizar, v. 1, n. 2, Rio de Janeiro, jan. /abr., p. 1 - 9, 2008. Disponível em: https://docplayer.com.br/2807913-A-avaliacao-da-aprendizagem-comoprocesso-interativo-um-desafio-para-o-educador.html. Acesso em: 26 mai. 2021.

BELOTTI, Salua Helena Abdalla; FARIA, Moacir Alves de. Relação professor/aluno. Saberes da Educação, v. 1, n. 1, p. 1 - 12, 2010. Disponível em: http://docs.uninove.br/arte/fac/publicacoes/pdfs/salua.pdf. Acesso em: 12 abr. 2021.

BITTENCOURT, Circe Maria Fernandes. Ensino de história: fundamentos e métodos. 4. ed. São Paulo: Cortez, 2011.

BRASIL. Lei no 9.394, de 20 de dezembro de 1996. Estabelece as Diretrizes e Bases da Educação Nacional. Brasília,1996. Disponível em:

http://www.planalto.gov.br/ccivil_03/leis/19394.htm. Acesso em: 11 set. 2021.

BRASIL. Portaria n⿳ 343, de 17 de março de 2020a. Dispõe sobre a substituição das aulas presenciais por aulas em meios digitais enquanto durar a situação de pandemia do Novo Coronavírus - COVID-19. Disponível em: http://www.in.gov.br/en/web/dou/-/portaria-n-343de-17-de-marco-de-2020-248564376. Acesso em: 11 set. 2021.

BRASIL. Portaria no 544, de 16 de junho de 2020b. Dispõe sobre a substituição das aulas presenciais por aulas em meios digitais, enquanto durar a situação de pandemia do novo coronavírus - Covid-19, e revoga as Portarias MEC n 343, de 17 de março de 2020, n 345, de 19 de março de 2020, e $\mathrm{n}^{\circ}$ 473, de 12 de maio de 2020. Disponível em: https://www.in.gov.br/en/web/dou/-/portaria-n-544-de-16-de-junho-de-2020-261924872. Acesso em: 11 set. 2021.

CAVALCANTI-NETO, Ana Lúcia Gomes; AQUINO, Josefa de Lima Fernandes. A avaliação da aprendizagem como um ato amoroso: o que o professor pratica? Educação em Revista, v. 25, n. 2, p. 223 - 240, 2009. Disponível em: https://doi.org/10.1590/S010246982009000200010. Acesso em: 24 mai. 2021.

FACHINETO, Sandra et al. AVALIAÇÃO DE APRENDIZAGEM EM MEIO A PANDEMIA DO CORONAVÍRUS NO BRASIL. Anuário Pesquisa e Extensão Unoesc São Miguel do Oeste, v. 5, p. e24090-e24090, 2020. Disponível em: https://unoesc.emnuvens.com.br/apeusmo/article/view/25090/14758. Acesso em: 30 ago. 2021.

FRANCO, Maria Amélia do Rosario Santoro. Prática pedagógica e docência: um olhar a partir da epistemologia do conceito. Revista Brasileira de Estudos Pedagógicos, v. 97, p. 534-551, 2016.2 Disponível em: https://www.scielo.br/j/rbeped/a/m6qBLvmHnCdR7RQjJVsPzTq/?format=pdf\&lang=pt.

Acesso em: 05 set. .2021.

GRANDISOLI, Edson; JACOBI, Pedro Roberto; MARCHINI, Silvio. Pesquisa Educação, Docência e a COVID-19. Universidade de São Paulo: Cidades Globais. Instituto de Estudos Avançados da USP, 2020. Disponível em: https://www.researchgate.net/profile/Edson- 
Grandisoli/publication/343473967_Pesquisa_Educacao_docencia_e_a_COVID19/links/5f2be15d458515b72906c59c/Pesquisa-Educacao-docencia-e-a-COVID-19.pdf.

Acesso em: 30 abr. 2021.

HODGES, Charles et al. A diferença entre ensino remoto de emergência e aprendizagem online. Revisão da Educause, v. 27, p. 1 - 12, 2020. Disponível em: https://www.translatetheweb.com/?from=en\&to=pt\&ref=SERP\&refd=www.bing.com\&dl=en \&rr=UC\&a=https\%3a\%2f\%2fer.educause.edu $\% 2$ farticles $\% 2 \mathrm{f} 2020 \% 2 \mathrm{f} 3 \% 2 \mathrm{fthe}$-differencebetween-emergency-remote-teaching-and-online-learning. Acesso em: 01 abr. 2021.

HOFFMANN, Jussara. Entrevista com Jussara Hoffmann: Por uma mudança efetiva da avaliação. [Entrevista concedida a Luiza Oliva]. Destaque em educação. Entrevista publicada edição 9 - Outubro/2005 da Revista Direcional Educador. Disponível em: http://destaquedu.blogspot.com/2013/10/entrevista-com-jussara-hoffmann-por-uma.html.

Acesso em: 05 jun. 2021.

HOFFMANN, Jussara. Avaliar: respeitar primeiro, educar depois. 2. ed. São Paulo: Mediação, 2010.

HOFFMANN, Jussara. Avaliar para promover: as setas do caminho. Porto Alegre: Mediação, 2011.

HOFFMANN, Jussara. Avaliação e educação infantil: um olhar sensível e reflexivo sobre a criança. Porto Alegre: Mediação, v. 18, 2012.

LAGUARDIA, Josué; PORTELA, Margareth Crisóstomo; VASCONCELLOS, Miguel Murat. Avaliação em ambientes virtuais de aprendizagem. Educação e pesquisa, v. 33, n. 3, p. 513-530, 2007. Disponível em: https://doi.org/10.1590/S1517-97022007000300009. Acesso em: 05 mai. 2021.

LUCKESI, Cipriano Carlos. Avaliação da Aprendizagem Escolar: estudos e proposições. 22a. ed. São Paulo: Cortez, 2013. Disponível em: https://fliphtml5.com/xvkas/grtn/basic. Acesso em: 15 abr. 2021.

LUCKESI, Cipriano Carlos. Avaliação em Educação: questões epistemológicas e práticas. São Paulo: Cortez, 2018.

MARTINS, Fernanda Adorno. Google Forms como ferramenta de apoio: experiência docente em meio a pandemia corona vírus. In: CONGRESSO INTERNACIONAL DE EDUCAÇÃO E TECNOLOGIAS ENCONTRO DE PESQUISADORES EM EDUCAÇÃO A DISTÂNCIA. 2020, São Carlos. Anais [...], São Carlos: UFSCAR, 2020. p. 1 - 8. Disponível em: https://cietenped.ufscar.br/submissao/index.php/2020/article/view/1809/1441. Acesso em: 16 mai. 2021.

MERCADO, Luís Paulo Leopoldo. Ferramentas de Avaliação na Educação Online.

Programa de Pós-Graduação em Educação -Universidade Federal de Alagoas -Brasil. 2008.

Disponível em: 
http://www.niee.ufrgs.br/eventos/RIBIE/2008/pdf/ferramientas_avaluacion.pdf. Acesso em: 03 set. 2021.

MOREIRA, José António Marques.; HENRIQUES, Susana.; BARROS, Daniela. Transitando de um ensino remoto emergencial para uma educação digital em rede, em tempos de pandemia. Revista Dialogia, n. 34, p. 351 - 364, jan./abr., 2020. Disponível em: https://doi.org/10.5585/Dialogia.N34.17123. Acesso em: 01 mai. 2021.

MOREIRA, José António Marques; SCHLEMMER, Eliane. Por um novo conceito e paradigma de educação digital online. Revista UFG, v. 20, 2020. Disponível em: https://www.revistas.ufg.br/revistaufg/article/view/63438. Acesso em: 27 mai. 2021.

NÓVOA, Antonio. Formação continuada - Aula Magna António Novoa. 2020. (1h18m50s). Disponível em: https://www.youtube.com/watch?v=7kSPWa5Nieo. Acesso em: 08 mai. 2021.

OLIVEIRA, Romualdo Portela et al. Análise das desigualdades intraescolares no Brasil. 2013. Disponível em: https://www.researchgate.net/profile/AdrianaBauer/publication/297723429_ANALISE_DAS_DESIGUALDADES_INTRAESCOLARES _NO_BRASIL/links/56e619ce08ae65dd4cc0e1ee/ANALISE-DAS-DESIGUALDADESINTRAESCOLARES-NO-BRASIL.pdf. Acesso em: 25 abr. 2021.

PALÚ, Janete; SCHÜTZ, Jenerton Arlan; MAYER, Leandro. Desafios da educação em tempos de pandemia. Cruz Alta: Editora Ilustração, 2020. Disponível em: https://www.researchgate.net/profile/Janete-

Palu/publication/349312858_DESAFIOS_DA_EDUCACAO_EM_TEMPOS_DE_PANDEM IA/links/602a572592851c4ed571ff33/DESAFIOS-DA-EDUCACAO-EM-TEMPOS-DEPANDEMIA.pdf. Acesso em: 15 mai. 2021.

PRODANOV, Cleber Cristiano; FREITAS, Ernani Cesar de. Metodologia do Trabalho Científico: Métodos e Técnicas de Pesquisa e do Trabalho Acadêmico. 2a. ed. Novo Hamburgo: Feevale, 2013.

SANTOS, Josiane Gonçalves. Avaliação do desenvolvimento e da aprendizagem. Curitiba: Ed. Fael, 2010.

SCHLEMMER, Eliane; FELICE, Massimo Di; SERRA, Ilka Márcia Ribeiro de Souza. Educação OnLIFE: a dimensão ecológica das arquiteturas digitais de aprendizagem. Educar em Revista, v. 36, 2020. Disponível em: https://doi.org/10.1590/0104-4060.76120. Acesso em: 30 abr. 2021.

SCHÖN, Donald. Os professores e sua formação. Portugal: Dom Quixote, 1997.

SILVA, Marco. Avaliação da aprendizagem em educação online: fundamentos, interfaces e dispositivos, relatos de experiências. São Paulo: Edições Loyola, 2006. 
SOUSA, Sandra Maria Zákia Lian. Avaliação da aprendizagem na legislação nacional: dos anos 1930 aos dias atuais. Estudos em Avaliação Educacional, v. 20, n. 44, p. 453-470, 2009. Disponível em: https://doi.org/10.18222/eae204420092039. Acesso em: 01 jun. 2021.

VIANNA, Deise Miranda; BARBOSA-LIMA, Maria da Conceição; ARAÚJO, Renato Santos. Mudaram minha sala de aula: E agora? Ciências em Foco, v. 14, 2021. Disponível em: https://econtents.bc.unicamp.br/inpec/index.php/cef/article/view/15484. Acesso em: 26 mai. 2021.

WEISZ, Telma; SANCHES, Ana. O diálogo entre o ensino e a aprendizagem. 2. ed. São Paulo: Ática, 2006.

Recebido em: setembro/2021. Aprovado em: novembro/2021. 